\title{
Maintenance Impact on Geothermal Drilling Operations. A Case Study Approach
}

\author{
Stanley M. Mburu ${ }^{1 *}$, James M. Wakiru ${ }^{1,2}$, Peter N. Muchiri1 ${ }^{1}$, Liliane Pintelon ${ }^{2}$ \\ ${ }^{1}$ Department of Mechanical Engineering, Dedan Kimathi University of Technology, Nyeri, Kenya \\ ${ }^{2}$ Centre of Industrial Management/Traffic and Infrastructure, KU Leuven, Heverlee, Belgium \\ Email: *mburustanley.m@gmail.com
}

How to cite this paper: Mburu, S. M. Wakiru, J. M., Muchiri, P. N., \& Pintelon, L. (2021). Maintenance Impact on Geothermal Drilling Operations. A Case Study Approach. American Journal of Industrial and Business Management, 11, 183-201.

https://doi.org/10.4236/ajibm.2021.112012

Received: January 3, 2021

Accepted: February 20, 2021

Published: February 23, 2021

Copyright (c) 2021 by author(s) and Scientific Research Publishing Inc. This work is licensed under the Creative Commons Attribution International License (CC BY 4.0).

http://creativecommons.org/licenses/by/4.0/

\begin{abstract}
This paper develops a simulation-based model to derive critical maintenance parameters towards optimizing a deep drilling rig availability and maintenance costs. Full factorial analysis is performed to derive the effects and interactions of the derived parameters, based on which ones with a significant effect on the availability and maintenance cost are selected. The case study based model incorporates maintenance, spares and workforce strategies for a geothermal drilling rig. The results offer essential maintenance decision support to both the management and maintenance team of the company and have the potential of further offering insights that eventually reduce the cost of drilling.
\end{abstract}

\section{Keywords}

Maintenance Cost, Geothermal, Non-Productive Time, Rig Availability, Drilling

\section{Introduction}

\subsection{Background}

Drilling is a significant operation in geothermal energy production. Geothermal energy is realized by tapping the underground steam by employing deep drilling rigs. The productivity and output of the geothermal plant, therefore, depends on the reliability of the drilling rig equipment and related support systems. A decline in the drilling rig reliability due to downtime or non-productive time can be attributed to two main factors: firstly, high non-productive time (NPT) can be occasioned by both operational and maintenance aspects. Secondly, NPT can be caused by external factors like the rock structure that could necessitate even the abandonment of a well. A critical contributor to NPT has been evidenced to 
retain maintenance-related downtime occasioned by both failure of the equipment and subsequent maintenance interventions.

A growing body of literature recognizes the significant adverse impact of maintenance-related downtime on plants or asset availability and profitability (Wakiru, Pintelon, Muchiri, \& Chemweno, 2019b; Wakiru, Pintelon, Muchiri, Chemweno, \& Mburu, 2020; Wakiru, Pintelon, Muchiri, \& Chemweno, 2020; Tambe \& Kulkarni, 2016). Such downtime primarily due to unforeseen failures, in many cases, would require additional unplanned resources like contracted service maintenance, which may also increase the downtime due to extended logistical requirements. An inherent characteristic of geothermal operations retains the remote locations of the operational sites, which may significantly contribute to extending the downtime due to logistical challenges. The remote location also extends lead times for spares required for maintenance. Together, these challenges significantly impact rig availability $\left(A_{r}\right)$, while affecting its profitability and eventually increasing the steam production cost (Elevli \& Elevli, 2010). These factors subsequently raise the cost of electricity.

It is argued that various parameters can be optimized towards reducing the downtimes and operational delays termed as the non-productive activities to warrant high availability and utilization, and consequently higher productivities and subsequently lower costs (Kansake \& Suglo, 2015). Maintenance has a significant role in mitigating downtime directly caused by failure and maintenance related to various subsystems in a drilling rig.

\subsection{Notations}

Throughout this paper, the following notations as illustrated in Table 1 are used:

\subsection{Study Aim and Motivation for the Research}

The world is moving towards green energy, where Kenya has been increasingly stepping towards this direction of generation of green energy. Driven by the need to increase the reliance on cost-effective sources of energy, Geothermal

Table 1. Notations adopted in the paper.

\begin{tabular}{cc}
\hline Response variables & Description \\
\hline$A_{r}$ & Rig availability (\%) \\
$C_{m}$ & Annual rig maintenance cost $(€)$ \\
\hline Model parameters & \\
\hline$T_{P M}$ & PM interval (Hours) \\
$\eta_{r p l}$ & Replace utilization (\%) \\
$\eta_{r p r}$ & Repair utilization (\%) \\
$L_{E_{d}}$ & Number of day shift engineers \\
$L_{E_{n}}$ & Number of night shift engineers \\
$L_{T_{d}}$ & Number of day shift technicians \\
$L_{T_{n}}$ & Number of night shift technicians \\
\hline
\end{tabular}


Development Company (GDC) was formed to spearhead the development of geothermal energy in the region. The company owns seven deep drilling rigs that have been commissioned to explore and drill geothermal wells for power generation intensively. GDC has a maintenance team that provides in-house maintenance while some specialized equipment where the maintenance personnel is inadequate to have been on contract service management. The effective maintenance policies employed are corrective due to unplanned failures and preventive block replacement. However, due to normal wear and tear, sometimes inadequate maintenance, and environmental effects, the rig equipment frequently fails and adversely affects the drill availability and maintenance cost. It is clear that according to Nyota \& Murigu (2016), only 6\% of the total drilling time was incurred as NPT for wells drilled in Olkaria, Kenya.

However, for the well under study, $6 \%$ of all the drilling time was solely maintenance-related NPT. From the graph in Figure 1, the deviation from the planned drilling days shows that non-productive activities majorly caused the deviation. The NPTs that resulted in extended drilling duration as shown in

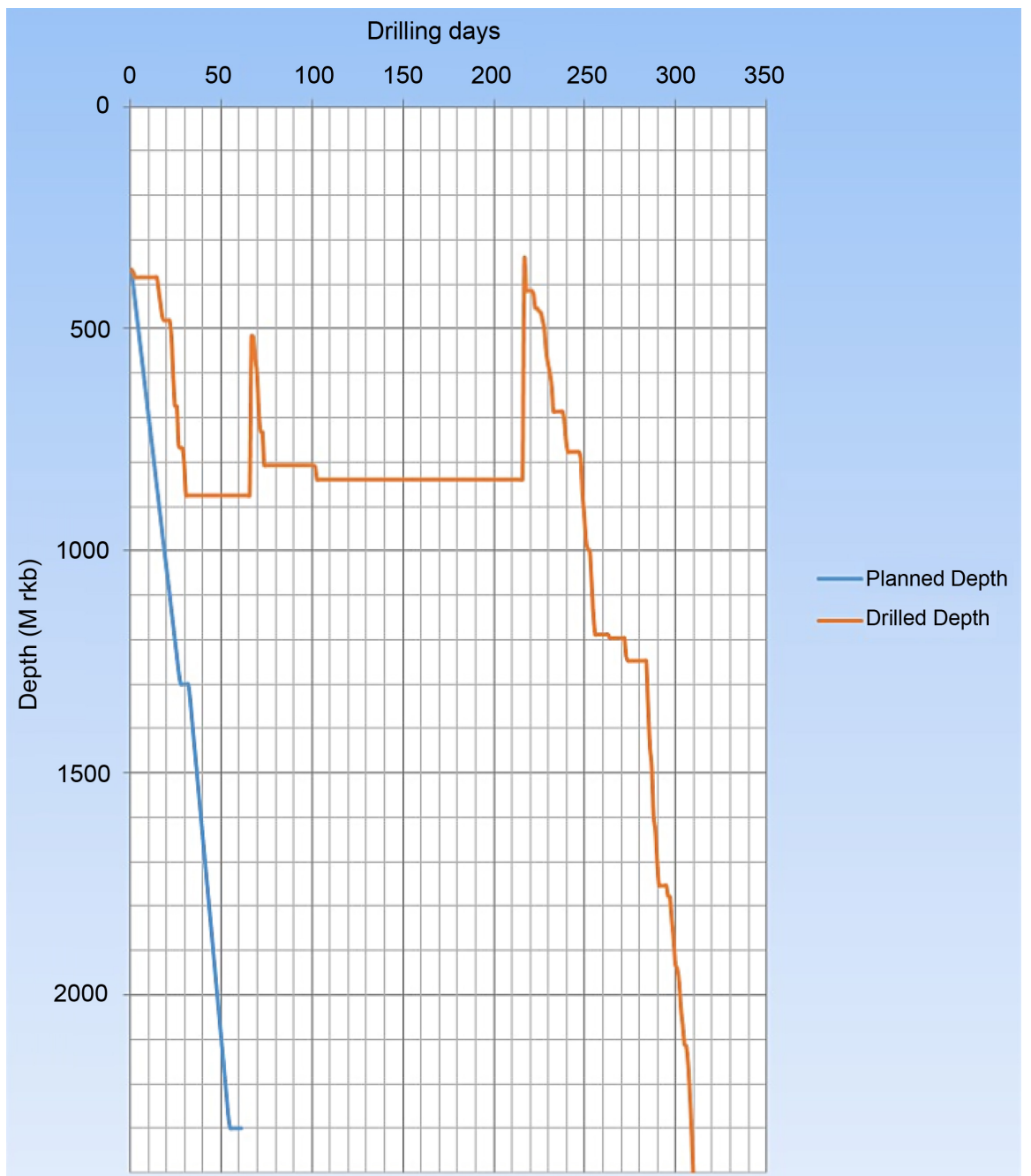

Figure 1. Sample planned drilling duration vs actual drilling durations. 
Figure 1 were drilling string sticking in the formation, time consuming fishing operation, lost time due to extended drilling materials lead time, long time taken to avail spares, unprecedented equipment failure, and untimely decision making. The flat curve between day 83 and day 212 was highly contributed by the drill string being stuck onto the formation as well as lead time on sourcing for fishing tools to work on the stuck string.

Moreover, due to the drilling rigs 24-hour operations, the scheduling of maintenance personnel in the two-shift often leads to downtime primarily when failure requiring certain skilled personnel occurs when the resource is unavailable. This signifies that addressing failure, maintenance and workforce scheduling of the drilling rig equipment; significant improvement can be realized, hence the need for this research in drilling rig maintenance.

Failure of the drilling rig equipment portends various risks. Among them includes increased maintenance cost due to running operational contracts, loss of revenue due to lack of stem for sale, long drilling duration, which inevitably leads to high drilling costs, drilling string sticking in the formation, expensive fishing operations, and loss of wells. Moreover, the primary failure of drilling rig equipment has the potential to propagate and lead to secondary failure on a piece of different equipment. For instance, when the power units fail, rotation is unavailable, and in this case, the outflow of drilling fluids is not right, hence sticking would be inevitable. Furthermore, when sticking occurs, the actions following might be fishing operations; these operations are expensive and would result in the cost of drilling shooting up. This could as well lead to sidetracking of the drilling, which means that the original drilled well profile necessitates being abandoned. In extreme cases that have happened is abandoning the well altogether, which ultimately would result in lost investments and time.

Optimizing maintenance would, therefore, assist in preventing the above from happening and thus improves the rig availability, while reducing the maintenance cost. When optimizing maintenance, it would also be prudent to consider the impact of maintenance activities on the reliability of the equipment, which affects the availability and system performance. A recent study that included the case study company (Company D) while deriving critical maintenance objectives, identified availability, maintenance scheduling and logistics support as critical (Wakiru, Pintelon, Muchiri, \& Chemweno, 2019a). The identified objectives signify the importance of addressing the rig availability within the premise of the logistical and scheduling constraints of operations. By improving reliability, the failures would reduce, and the overall life of the equipment would be improved; hence a balance must be achieved on the spare replacement and other maintenance actions like repair. Work in this area is extensive but is primarily concerned with the maintenance and spares policies, and often disregard the impact of workforce or workforce on the system performance.

The main objective of this study is to investigate the effectiveness of the current maintenance policies and the workforce schedule in place. The present 
study seeks to identify the critical maintenance and workforce scheduling parameters, which, when focused on, results in optimized drilling rig availability and reduced maintenance cost. To the best of the authors' knowledge, this is the first study that optimizes maintenance, spares and workforce strategies simultaneously.

The next sections of this study are as follows. In Section 2, we review relevant literature, while in Section 3, the methodology followed is outlined. Section 4 presents the results, and Section 5 offers a discussion with managerial implications. Lastly, Section 5 concludes and provides future research suggestions.

\section{Relevant Literature Review}

Maintenance refers to the activities that are necessary to keep or restore equipment to a specified operating condition. These activities aim to maximize equipment availability in a specified operating condition, which allows the realization of the desired output concerning quality and quantity. The outputs have to be realized cost-effectively and conform to the stipulated safety and environmental regulations (Pintelon \& Gelders, 1992). To achieve effective maintenance management towards optimizing the performance of the plant, two critical aspects require to be considered: maintenance planning and workforce scheduling also corroborated by Jia \& Zhang (2020).

Maintenance planning involves articulating the maintenance policies that are effective in mitigating equipment reliability and failures. It is crucial and essential for continuity of operations and a clear understanding of the maintenance management program (Dhillon, 2002). Relevant policies in this research are preventive $(\mathrm{PM})$, corrective $(\mathrm{CM})$ and condition-based maintenance (CBM). $\mathrm{CBM}$ is intertwined with predictive maintenance $(\mathrm{PdM})$ and prognostics and health management (PHM). CBM is defined as a decision-making strategy that considers the condition of the system or the component to decide on performing maintenance. PM is the action performed on a time or machine run based schedule that detects a defect, preclude, or mitigate degradation of a component or system to sustain or extend its useful life through controlling degradation to an acceptable level (Sullivan, Pugh, Melendez, \& Hunt, 2010). Corrective maintenance is the predominant naturally occurring maintenance policy, which is employed following the failure of the components in a system. Various maintenance activities subsumed in the CM policy are described in detail in the ISO 14224 (2016) and include a replacement, repair, adjustment, among others. A significant number of research considering corrective maintenance often relies on the replacement to attain the state "as good as new" or combine replacement and minor repair, where the state "as bad as old" is attained (Dijoux, Fouladirad, \& Nguyen, 2016). However, in real life, other maintenance activities like adjusting are often employed, hence disregarding them would lead to suboptimal maintenance solutions.

Workforce or labor planning and scheduling are essential for the success of 
maintenance management. Alfares (2003) categorizes workforce scheduling into three categories. The first category entails the workforce shift, time-of-day schedule, while the second retains a day-of-week schedule and, lastly, a tour schedule, a hybrid of the first two categories. An effective human resources plan provides various mechanisms designed to get rid of talent gaps, which may exist between the organization's supply of labor and its demand for the same in the plant operational context. For an organization to have an adequate workforce for maintenance activities, there ought to be sufficient planning considering the various maintenance requirements, time and operational demand. The planning enables the organization to have the right skills as well as the right labor distribution. It is therefore essential to optimize the time of the technical maintenance staff as it influences the overall productivity and maintenance efficiency. The implementation of continuous system monitoring and the analyses of planned, scheduled and completed maintenance tasks significantly improves equipment availability and cost reduction. Several studies have been done in this line of workforce scheduling which includes Al-Shayea (2012), Alshareef \& Saber (2018), and Emovon, Lilly, \& Ogaji (2012). As also corroborated by Alshareef \& Saber (2018), the evaluation of the impact of the technical personnel (number and schedule) on the plant availability and overall cost of maintenance has seldom been done. Moreover, the schedule optimized in these studies disregards the randomness introduced by failure and different probabilistic maintenance interventions demands that directly interrupt the schedules. This research, therefore, seeks to find out the impact of the technical personnel schedule to the maintenance cost and system availability, while considering the plant failure and maintenance demands.

An essential aspect of maintenance management retains the identification of critical parameters that significantly affect the performance of a system. Engineers in practice and research often perform one-factor-at-a-time (OFAT) experiments, which vary only one factor or variable at a time while keeping others fixed to derive their impact on the performance measure (Wakiru et al., 2019b). However, statistically designed experiments that vary several factors simultaneously are more efficient when studying two or more factors because of their interactive nature (Czitrom, 1999). A designed experiment is a more effective way to determine the impact of two or more factors on response. In this case, both the main effects which uphold the OFAT concept and the interaction effects, which derive the impact of two or more factors can be derived. Studies like those of Bouslah, Gharbi, \& Pellerin (2018) and Wakiru et al. (2019b) suggest that measurement of the sizes retained by main effects and interaction effects offers plausible insights and decision support.

Considerable research in maintenance that follows the line of this research is by Wakiru et al. (2019b). The research modelled the operation and maintenance of an engine operating in a thermal power plant. In their study, they optimized the PM interval, spares fill-rate, and corrective maintenance utilization probabilities. However, their study ignored workforce scheduling which is a vital aspect 
of maintenance management. Moreover, the classification of corrective maintenance activities did not follow set maintenance standards like ISO 14224, where maintenance activities are categorized for ease of reference and wholesome accountability. Lastly, the study did not use the maintenance cost $\left(C_{m}\right)$ as a critical performance measurement which they suggested for future work; in this study, we employ both availability and maintenance cost.

This research develops a framework where a simulation-based model is employed to derive critical variables for optimal drilling rig availability and maintenance costs. Various maintenance policies, in this case, various corrective maintenance, preventive maintenance actions are derived from empirical maintenance data and aligned with ISO 14224 standard. The model further integrates workforce scheduling (day and night shifts) while optimizing the drilling rig availability and maintenance costs.

\section{Methodology}

The methodology includes several steps. Among them is data collection, pre-processing, and exploration. The steps have been discussed below.

\subsection{Data Collection and Pre-Processing}

The data collected was for a well drilled in Kenya, between 2017 and 2018. The entire drilling days were 311 against the planned 55 days. The extended actual drilling days are demonstrated to be significant, and the well costs were similarly high compared with other wells.

Data were extracted from reports in their raw format, which included the drilling logs, well completion reports, maintenance logs, and system failure data. The events of failure and maintenance were referenced to the date and time of event occurrence and finalization of the event; hence rig re-start operating. The raw data collected was then organized in an excel sheet in an addressable manner for ease of processing and analysis. The data were further categorized according to the subsystems and in order of occurrence. This was the final format, which was then ready for exploration and extracting of model parameters.

\subsection{Data Exploration}

In this phase, the pre-processed data was explored to retrieve various aspects of the data to inform the modelling. The drilling rig operations can be categorized into nine subsystems as shown in Table 2.

\subsection{Model Parameter Extraction}

For the rig subsystems, as indicated in Table 2, various parameters were extracted from the empirical data, as addressed subsequently.

Table 3 illustrates the sample model parameter characteristics relating to the different subsystems extracted from the data. This includes the time to initial failure (TIF) which was computed with respect to the commissioning date and 
Table 2. Rig subsystems categories.

\begin{tabular}{ll}
\hline \multicolumn{1}{c}{ Subsystem } & \multicolumn{1}{c}{ Purpose } \\
\hline Air drilling system & $\begin{array}{l}\text { Supply highly compressed air to the drilling string to push the } \\
\text { cuttings to the surface. It comprises primary compressors } \\
\text { and the secondary compressors. }\end{array}$ \\
Consists of the draw works and other pulley devices used to lift \\
and lower the drilling string into and out of the well.
\end{tabular}

Table 3. Subsystem modelling times.

\begin{tabular}{ccc}
\hline Subsystem & $\begin{array}{c}\text { Time to initial } \\
\text { failure (Hrs.) }\end{array}$ & $\begin{array}{c}\text { Time to next failure (TNF) } \\
(\text { Hrs. })\end{array}$ \\
\hline Air drilling system & 255 & $9+$ WEIB $(240,0.376)$ \\
Hoisting system & 679 & $4+\operatorname{EXPO}(606)$ \\
Power system & 1963 & $2+$ WEIB $(289,0.339)$ \\
Well control system & 240 & $412+$ WEIB $(121,0.235)$ \\
Well monitoring system & 2022 & UNIF $(122,2.92 \mathrm{e}+003)$ \\
Circulating system & 5116 & $-0.001+$ EXPO $(77.7)$ \\
Mechanical handling system & 4836 & 5116 \\
Top drive system & 413 & $2+$ WEIB $(320,0.339)$ \\
\hline
\end{tabular}

initial failure date for the respective subsystem. It also includes TNF (time to next failure) probability distribution for each subsystem. The failure frequency was the rate at which the subsystems of the systems were failing. This also gives the counts of the failures and thus gives the system with the highest number of failures, which could later be a point of interest for further research. The time-to-next-failure (TNF) for each subsystem was derived from the data. TNF 
was based on the difference between the date and time of the current and previous failure of a specific subsystem. The TNF was thence fitted to a probability distribution thus taking different forms (WEIB, EXPO, and UNIF) depending on the data characteristics. The repair times for both the preventive and corrective maintenance were extracted from the categorized data. This depicts the time spent while undertaking the repairs and or replacement during either corrective or preventive maintenance interventions.

While carrying out maintenance on the rig, two main maintenance strategies are explored, which include corrective (CM) and preventive maintenance (PM). Under CM, the different maintenance actions derived from the empirical maintenance data were referenced to the standard maintenance actions described in ISO 14224 (2016). These include strategies underlying the replacement of failed components with newly manufactured spares, repairing the failed components, adjusting different aspects that cause downtime, and finally unclogging the various components such as filters and compressors. The various corrective maintenance actions are indicated in Table 4, together with the estimated respective mean time to repairs (MTTR) in hours and their respective probability of utilization. These parameters are further utilized in the simulation-based model, which is discussed in the following sections.

\subsection{Modelling}

Simulation modelling is typically a cost-effective way of substituting physical experimentation and offers flexibility to incorporate uncertainties that are experienced in real life. In this case, Arena simulation was used to model and simulate the geothermal drilling rig, where subsystems make the whole system. Statistical analysis was used to formulate the data and derive the model parameters, which contains all the parameters of actual drilling.

The schematic representation of the conceptual framework of the model in Figure 2 mimics the running and maintenance of the rig subsystems. To model the subsystem degradation and reliability, we adopt the approach of Wakiru et al. (2019b), where we introduce an impact factor (IF) with values 0 to 1 . The impact factor is a variable that impacts the reduction of the virtual age of the subsystem, in this case, the time to next failure depending on the maintenance intervention undertaken on the unit. On the other side, the failure severity,

Table 4. Maintenance actions with respective MTTR.

\begin{tabular}{ccccc}
\hline \multirow{2}{*}{$\begin{array}{c}\text { Maintenance } \\
\text { action }\end{array}$} & MTTR (hrs.) & \multicolumn{3}{c}{ Probability utilization } \\
\cline { 3 - 5 } & & (All subsystems except TDS) & Air \& power & TDS \\
\hline Replace & 22.67 & 0.4091 & \\
Repair & 28.00 & 0.4772 & 0.2222 \\
Adjust & 21.40 & 0.1136 & & \\
Unclog & 22.00 & & 0.2353 & 0.1111 \\
Reset & 1.00 & & & 0.6667 \\
\hline
\end{tabular}






Figure 2. Conceptual framework of the developed simulation model.

which indicates the seriousness of the subsystem state, follows a semi Markov decision process and is influenced by the last state and the maintenance intervention undertaken on the specific subsystem. As the system is operational (the rig is running), the initialization of all the subsystems is done. In this case, the respective failure severities, impact factors, and the individual subsystem time to next failure. As the system is operational, the simulation time is evaluated, if the PM interval $\left(T_{P M}\right)$ is reached, then PM is conducted. PM entails a block replacement policy, and different subsystems retain different PM intervals. For instance, the top drive has a PM interval of 500 hours, while the well handling unit has 1500 hours. Therefore, the PM intervals are graduated to either $(500,1500$, 4000) hour service interval, and the MTTR for PM intervention is 16.6667 hours.

During PM, the 500 hours PM requires one engineer and two technicians, while for the others, requires one engineer, two technicians and a contractor representative. Similarly, we factor in the contracted service contracts for subsystems like the air compressors in the PM costs. After the PM intervention, next to PM interval is scheduled while the failure severity (FS) and IF of the respective subsystem is updated. Lastly, the PM costs are updated, which included la- 
bor and spare costs. If PM interval has not been reached, there are possibilities of unplanned failures which are addressed using various corrective maintenance actions. Four main CM actions are randomly prescribed using the probability utilizations and incur MTTR (expressed exponentially) both derived from empirical data, as illustrated in Table 4. The replace action entails the replacement of the failed component with a new spare. After the CM interventions, the FS and IF of the subsystem are updated. Additionally, the CM costs, which included the labor and spare costs, is also updated.

To model the workforce scheduling in the subject rig, the rig operations run on two shifts (day and nightshifts) running 06:00 a.m. - 06:00 p.m., and 06:00 p.m. - 06:00 a.m., respectively. During the day shift, the critical maintenance personnel available that this study accounts for are one drilling engineer and two mechanical technicians, while during the nightshift, we have one mechanical technician alone.

\subsection{Performance Measures}

The simulation-based model is designed to derive two key performance measures, i.e., the rig availability $\left(A_{r}\right)$ and the total annual maintenance cost $\left(C_{m}\right)$. As shown in Equation (1), the drill availability, which is the percentage of the time the drill is operational, accounts for the downtime of the rig. The downtime includes the actual maintenance duration and lead times occasioned by spare sourcing. Equation (2) computing the annual maintenance cost for the rig, considers the spare and labor costs.

$$
\begin{gathered}
A_{r}=\frac{\text { Drilling hours }}{\text { Drilling hours }+ \text { Downtime }} * 100 \\
C_{m}=\frac{\text { PMLaborCost }+ \text { PMSpareCost }+ \text { SpareCost }+ \text { CMLaborCost }}{\text { numberofyears }}
\end{gathered}
$$

\section{Results and Discussion}

The model was set up to run for a simulation time of 43,800 hours, which signifies the five years of rig operation. Since the model starts with no activity, to attain steady-state, we introduced a warm-up period of 0.083 hours and to reduce the half-width to acceptable levels, and we employed 75 replications as computed herewith. Based on the $C_{m}$ the half-width of \pm 2730 while using ten replications, we reduced it to a level \pm 1000 using the following Equation (3).

$$
n=\frac{n_{o} * h_{o}^{2}}{h^{2}}
$$

where $n_{o}$ is the number of current replications, $h_{o}$ is the current half-width, $h$ is required half-width, and $n$ is the required replications.

$$
n=\frac{10 \times 2730^{2}}{1000^{2}}=75 \text { replications }
$$

In this section, we report the model results and evaluate the impact of PM in- 
terval, repair maintenance action utilization, and nightshift technicians on the performance measurements of the systems in Section 4.1. In Section 4.2, we perform a full factorial experiment and derive the main effects and interaction effects.

\subsection{Model Results}

After running the simulation, the availability of $84.503 \%$ and $C_{m}$ of $€ 213,090$ was generated. The expected rig availability was $82.02 \%$. This is the value obtained from the raw data and gives a value that validated the model availability with an acceptable range of $\pm 10 \%$.

To evaluate the impact of PM interval on the performance measures, we varied the PM interval from 250 hours to 750 hours, and the results are illustrated in Figure 3.

From Figure 3, the results depict that the $A_{r}$ increases by $28.4 \%$ from $67 \%$ to $86 \%$ and the $C_{m}$ reduces by $32.7 \%$ from $€ 275626$ to $€ 185540$ as the $T_{P M}$ varies from 240 hours to 800 hours. This is attributed to a decrease in the number of PM activities. This can be assisted by the employment of predictive maintenance, which at relatively low cost will ensure that the lube is within the required quality standard. The scenario is also attributed to reduced PM-related delays time. This is because as the $T_{P M}$ increases, the hours lost due to servicing the system decreases. The results appear to make sense and to be compatible with our expectations.

To investigate the impact of the workforce, we varied the number of technicians in the nightshift, and the results are illustrated in Figure 4. The plot insinuates that retaining one technician at night significantly adversely affects the rig availability while the $C_{m}$ is not significantly affected. Increasing $L_{T_{n}}$ to 2 , is shown to increase both the $A_{r}$ and $C_{m}$ moderately. A further increase is depicted to marginally lower $A_{r}$ and $C_{m}$ moreover, levelized from 3 nightshift technicians. This finding confirms the precondition for the various maintenance tasks. Each maintenance task had different requirements in terms of manpower resource allocation varying from one technician to three technicians. It therefore implies

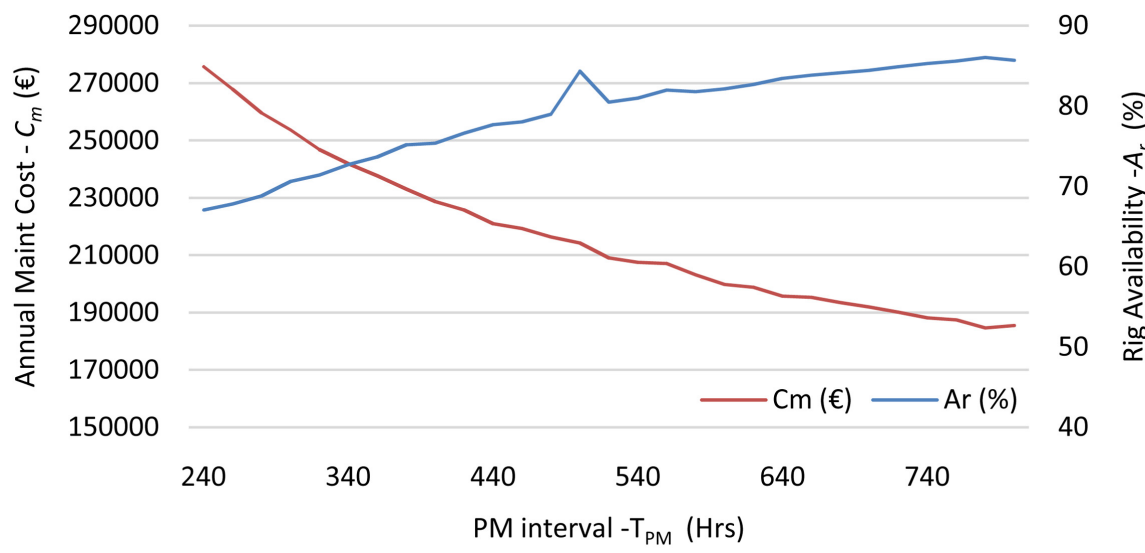

Figure 3. Impact of varying PM interval $T_{P M}$ on rig performance. 
that the optimal value for $L_{T_{n}}$ is 2 or 3 technicians since beyond these values, no significant change is noticed. Moreover these results confirm the contribution of inadequate manpower to the high NPT as illustrated earlier in Figure 1. To evaluate the effect of predominantly relying on repairing of the subsystems, we varied the repair maintenance action utilization $\left(\eta_{r p r}\right)$. As shown in Figure 5, an increase in $\eta_{r p r}$ leads to a decrease in the rig availability $A_{r}$ and an increase in the $C_{m}$. Two vital factors can be attributed to this finding. Firstly, an increase in repair activities is subjected to a higher repair duration compared to the other maintenance actions like replace. This implies that the effect leads to an increase in downtime due to repair actions, hence reducing availability. Likewise, the increased repair-related activities lead to a significant increase in the labor cost incurred, hence an increase in maintenance cost. Secondly, repair intervention has an adverse effect on the subsystem reliability, more so in this case, where we consider imperfect maintenance. The reduced reliability of the subsystem means that its failure frequency increases, hence increased interventions which impact negatively on the maintenance cost and availability hence a reduction in availability and an increase in the $C_{m}$.

However, despite the results (Figures 3-5) meeting our expectations, the

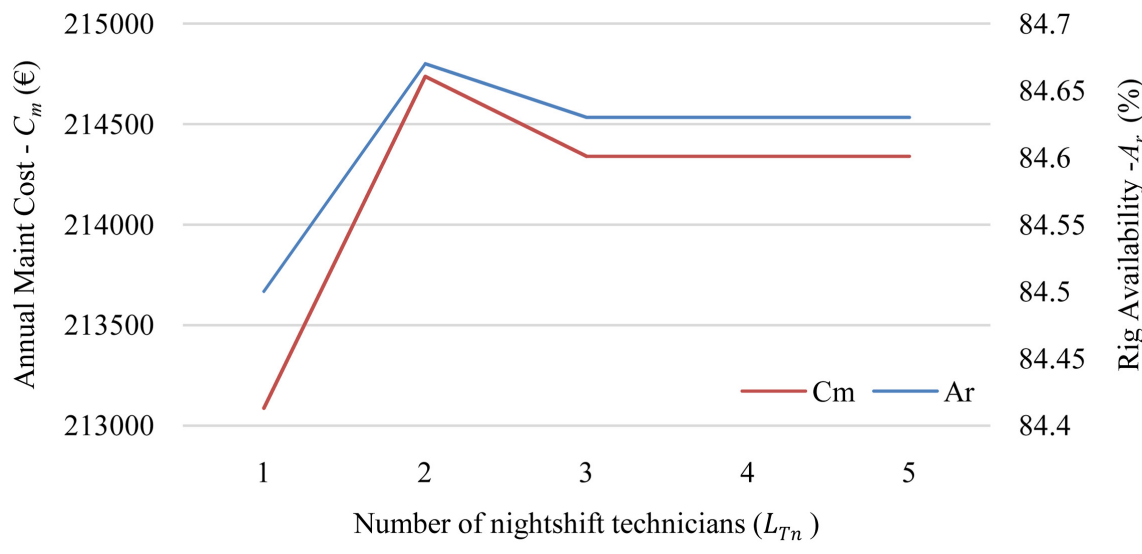

Figure 4. Impact of varying the number of nightshift technicians on the rig performance.

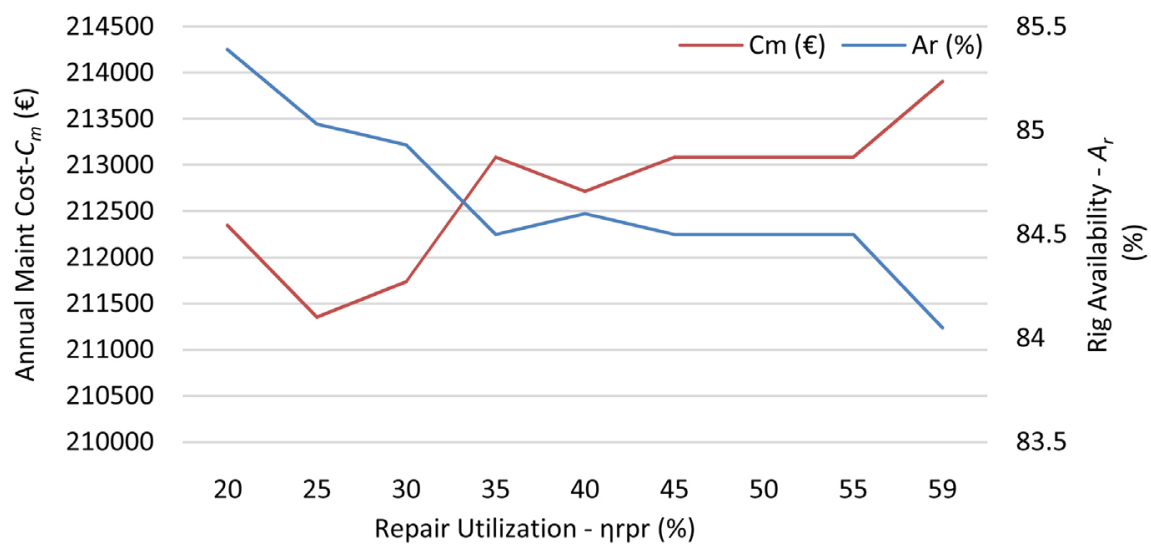

Figure 5. Impact of varying repair maintenance action utilization $\left(\eta_{r p r}\right)$ of rig performance. 
non-linearity of the relationship may infer that the variable $\eta_{r p r}$ does not proportionately impact the performance measures; hence there is a likelihood that other control variables are interacting with these variables. To investigate this phenomenon, we undertake a full factorial experiment in the following section.

\subsection{Full Factorial Effects and Interactions Experiment Results}

A 2-factor complete factorial design experiment was conducted to determine the variables retaining a significant influence on the responses under research. The variables employed with their respective ranges are shown in Table 5. The respective variable ranges illustrated in Table 5 were derived according to the procedure used by Wakiru et al. (2019b).

\subsubsection{Main Effects Results}

Table 6 shows the effects of independent variables on the two main performance measures $A_{r}$ and $C_{m}$.

While evaluating the main effect sizes impact on $A_{r}$, it can be seen that $T_{P M}$ had the most significant impact, with an average increase of $4.06 \% . L_{E_{d}}$ (0.59\%), $L_{E_{n}}(0.63 \%)$ provide a marginal improvement of $A_{r}$ On the other hand, as expected, $T_{P M}$ likewise retained the most significant positive impact on the maintenance cost $\left(C_{m}\right)$, with an average reduction of $€ 34,255.91$. The changes in $\eta_{r p r}$ from a low level to a higher one demonstrate a modest reduction

Table 5. Variable ranges used in the full factorial experiment.

\begin{tabular}{ccc}
\hline Notation & Description & Ranges \\
\hline$T_{P M}$ & PM interval (hrs.) & $250-750$ \\
$\eta_{r p l}$ & Replace utilization (\%) & $20-48$ \\
$\eta_{r p r}$ & Repair utilization (\%) & $25-51$ \\
$L_{E_{d}}$ & Number of Day shift engineers & $1-3$ \\
$L_{E_{n}}$ & Number of Nightshift engineers & $1-3$ \\
$L_{T_{d}}$ & Number of Day shift technicians & $1-3$ \\
$L_{T_{n}}$ & Number of Nightshift technicians & $1-3$ \\
\hline
\end{tabular}

Table 6. Main effects sizes of various control variables.

\begin{tabular}{ccc}
\hline \multirow{2}{*}{ Control variables } & \multicolumn{2}{c}{ Performance measures } \\
\cline { 2 - 3 } & Availability $A_{r}(\%)$ & Maintenance cost $C_{m}(€)$ \\
\hline$T_{P M}$ & 4.06 & $-34,255.91$ \\
$\eta_{r p l}$ & -0.26 & $22,128.69$ \\
$\eta_{r p r}$ & -0.59 & -3848.3 \\
$L_{E_{d}}$ & 0.59 & 6087.87 \\
$L_{T_{d}}$ & -3.5 & $66,914.16$ \\
$L_{E_{n}}$ & 0.63 & 6036.48 \\
$L_{T_{n}}$ & -3.5 & $66,928.38$
\end{tabular}


of $C_{m}$ by $€ 3848.30$. This can be attributed to the reduction of spare-related costs due to lowering the replacement utilization affected when $\eta_{r p r}$ increases. These results indicate that an increase in the PM interval and repair maintenance action utilization, while all the other control variables are constant, would generate a positive impact on $C_{m}$.

On the contrary, an increase in both dayshift and nightshift technicians $\left(L_{T_{d}}\right.$ and $L_{T_{n}}$ ) adversely affects both $A_{r}$ and $C_{m}$. This may signify that the number of technicians is adequate to address the drilling rig maintenance. On the flip side, an increase in the dayshift and nightshift engineers $\left(L_{E_{d}}\right.$ and $\left.L_{E_{n}}\right)$ is shown to impact the $A_{r}$ positively but negatively impact the $C_{m}$. On the other hand, increased reliance on spare replacements leads to a negative impact on $A_{r}$ by $0.26 \%$ and a significant increase in the $C_{m}$ by $€ 22,128.69$. This is attributable to the use of new parts hence the modelled $C_{m}$ takes a higher value.

\subsubsection{Interaction Effects Results}

Table 7 presents a sample of two-factor interaction effect sizes incorporating the various control variables defined with their respective ranges in Table 5.

To understand the interactions in Table 7, the control variables notations can be referred from Table 1 . Further, while considering the interaction of $T_{P M}$ and $\eta_{r p r}$ it is shown that the effect is a marginal increase in $C_{m}$. However, while considering individual main effects shown in Table 7, both $T_{P M}$ and $\eta_{r p r}$ derived significant reduction in the $C_{m}$. The results appear to make sense and to be compatible with our expectations. An increase in the PM interval leads to an increase in corrective maintenance interventions, due to the expected surge in the failure of the equipment. Therefore, increasing the utilization of repair maintenance action compromises the reliability of the equipment, especially in the situation where preventive renewal instances have been reduced.

Table 7. A sample of interaction effects sizes of the control variables.

\begin{tabular}{|c|c|c|c|c|c|}
\hline \multirow{2}{*}{ Control variables } & \multicolumn{2}{|c|}{ Interaction effect sizes } & \multirow{2}{*}{$\begin{array}{c}\text { Control } \\
\text { variables }\end{array}$} & \multicolumn{2}{|c|}{ Interaction effect sizes } \\
\hline & $A_{r}(\%)$ & $C_{m}(€)$ & & $A_{r}(\%)$ & $C_{m}(€)$ \\
\hline$T_{P M}+L_{T_{d}}$ & 1.3 & $-11,409.74$ & $\eta_{r p l}+L_{E_{n}}$ & -0.03 & 1622.06 \\
\hline$T_{P M}+L_{T_{n}}$ & 1.3 & $-11,467.04$ & $\eta_{r p l}+L_{E_{n}}$ & -0.06 & 1674.00 \\
\hline$\eta_{r p l}+L_{T_{d}}$ & -0.09 & 8413.27 & $\eta_{r p r}+L_{E_{n}}$ & -0.05 & -1316.01 \\
\hline$\eta_{r p l}+L_{T_{n}}$ & -0.08 & 8407.98 & $\eta_{r p r}+L_{T_{d}}$ & -0.2 & -1207.49 \\
\hline$L_{T_{n}}+L_{E_{n}}$ & 0.22 & 5851.03 & $\eta_{r p r}+L_{E_{n}}$ & -0.09 & -1335.45 \\
\hline$L_{T_{d}}+L_{T_{n}}$ & 4.24 & $-59,649.77$ & $\eta_{r p r}+L_{T_{n}}$ & -0.17 & -1280.74 \\
\hline$L_{T_{n}}+L_{E_{n}}$ & 0.221 & 2882.42 & $L_{E_{d}}+L_{T_{d}}$ & 0.26 & 2924.25 \\
\hline$\tau_{P M}+\eta_{r p l}$ & 0.07 & 1114.04 & $L_{E_{n}}+L_{E_{n}}$ & -0.43 & -3555.09 \\
\hline$\tau_{P M}+\eta_{r p r}$ & 0.12 & 21.98 & $L_{E_{d}}+L_{T_{n}}$ & 0.26 & 2910.50 \\
\hline$T_{P M}+L_{E_{d}}$ & -0.11 & 79.03 & $L_{E_{n}}+L_{T_{n}}$ & 0.22 & 2882.43 \\
\hline$T_{P M}+L_{E_{n}}$ & -0.09 & 15.49 & $\eta_{r p l}+\eta_{r p r}$ & 0 & -1946.05 \\
\hline
\end{tabular}


A significant and exciting finding of the interaction experiment retains the interaction effects of $L_{T_{n}}$ and $L_{T_{d}}$. As shown in Table 7, the simultaneous increase in both the day and night number of technicians significantly increase the $A_{r}$ and highly reduce the $C_{m}$. This interaction results positively improve the rig performance despite the individual main effect of the two variables adversely affecting the rig performance. This aspect may correlate to an increase in maintenance requirements in both the shifts equally, hence increasing technicians in both the shift can address the situation adequately.

In the light of reported main effects and interaction between the various variables, it is conceivable that relying on the main effects as has been the norm in many maintenance optimizations, may offer adverse decision support when implemented without considering the interactions.

\section{Managerial Implications}

The study has demonstrated the development of a simulation-based model that incorporates maintenance, spare, and workforce policies. Moreover, the model retains scalability and can be implemented in real life. The study is significant for maintenance engineers seeking to optimize maintenance by evaluating the various maintenance, spares and workforce variables. A significant application for a plant could entail studies or analysis of changing spares supplier where the expected cost and sourcing lead time could be incorporated in such a model to enable a cost-benefit analysis on the decision to make. Similarly, workforce utilization and scheduling can further be enhanced using this model. The model possesses the capacity to evaluate alternative workforce options compared to the current one modelled where contract maintenance services can be compared.

While reviewing workforce scheduling, this study demonstrates the importance of incorporating random system behavior while deriving such a schedule. While most research in this line of thought has independently derived the workforce schedule based on deterministic labor demand and models, this study has employed not only stochastic attributes but also included other probabilistic maintenance requiring staff. The use of stochastic maintenance action utilization and workforce schedule considering day and night shift has proven our approach as a promising alternative to statistical models conventionally utilized.

The study has shown the importance of evaluating not only the main effects of variables using the one factor at a time (OFAT) rule but also the interactions while seeking to optimize maintenance. One of the key findings of this research is the significant interaction between the workforce distribution in the day on one side and nightshift. This information is critical to the maintenance management as it guides the management in deciding the scheduling of the engineers and technicians in the drilling rigs, to attain a high scheduled utilization. To implement this, the maintenance manager should, for instance, introduce extra personnel in the subject rig. In situations where this may be impossible, an alternative option is to organize a workforce sharing program where technicians and engineers may be attached to more than one drilling rig, which is nearby. 
The study has further demonstrated the need for spares subsumed in both corrective and preventive replacement. In real life, determining the stocking policy is not straightforward in the absence of a decision support framework, owing to the stochasticity of time characteristics like repair, diagnosis, and sourcing lead times. The maintenance manager could implement this strategy that considers spare part replacement (e.g., a pre-defined fill rate for the spares) together with other maintenance strategies like repair and adjustment, and undertake a cost-benefit analysis of the strategies. Furthermore, maintenance costs would offer much-required insights on the trade-off between spares availability and reliance on corrective maintenance strategies utilization.

\section{Conclusion}

The research study has developed a simulation-based model that investigates the various maintenance variables that significantly impact the availability and the annual maintenance cost of a system, in this case, a drilling rig. A full factorial analysis was employed to analyze the effects and interactions of the various maintenance and workforce variables, hence derive the critical variables. From the analysis of the results, the preventive maintenance interval and workforce distribution were shown as the critical maintenance-related parameters significantly influencing the optimization of the rig availability and maintenance costs. These findings have a significant implication in understanding the parameters that can further be investigated while carrying out maintenance decision making. If enhanced, the results would significantly improve the maintenance strategies, resource allocations and ensure priorities are set right to improve the availability of the rig and improve the $C_{m}$ and eventually the drilling economics.

However, a balance of decision variables used ought to be struck by considering their effects, interactions, experience, and expert knowledge. The research lays a groundwork for future studies in the geothermal field considering other maintenance strategies like condition-based maintenance, with their possible interactions towards a robust optimization model. On the other hand, the research has its limitations as it considered PM and CM policies primarily, whereas additional maintenance and restorative strategies identified like condition monitoring, and opportunity based maintenance could be incorporated in future research. Workforce scheduling and distribution can as well be classified according to designation and skill to investigate the optimized distribution of mechanical and electrical personnel among other personnel.

\section{Conflicts of Interest}

The authors declare no conflicts of interest regarding the publication of this paper.

\section{References}

Alfares, H. K. (2003). Flexible 4-Day Workweek Scheduling with Weekend Work Fre- 
quency Constraints. Computers and Industrial Engineering, 44, 325-338. https://doi.org/10.1016/S0360-8352(02)00192-4

Alshareef, A., \& Saber, A. Y. (2018). An Application of Particle Swarm Optimization (PSO) to Dynamic Unit Commitment Problem for the Western Area of Saudi Arabia. $J K A U, 29,21-32$.

Al-Shayea, A. M. (2012). Maintenance Capacity Planning: Determination of Maintenance Workforce. Engineering, 4, 37-43. https://doi.org/10.4236/eng.2012.41006

Bouslah, B., Gharbi, A., \& Pellerin, R. (2018). Joint Production, Quality and Maintenance Control of a Two-Machine Line Subject to Operation-Dependent and Quality-Dependent Failures. International Journal of Production Economics, 195, 210-226. https://doi.org/10.1016/j.ijpe.2017.10.016

Czitrom, V. (1999). One-Factor-at-a-Time versus Designed Experiments. The American Statistician, 53, 126-131. https://doi.org/10.1080/00031305.1999.10474445

Dhillon, B. S. (2002). Engineering Maintenance: A Modern Approach. Boca Raton, FL: CRC Press. https://doi.org/10.1201/9781420031843

Dijoux, Y., Fouladirad, M., \& Nguyen, D. T. (2016). Statistical Inference for Imperfect Maintenance Models with Missing Data. Reliability Engineering \& System Safety, 154, 84-96. https://doi.org/10.1016/j.ress.2016.05.017

Elevli, S., \& Elevli, B. (2010). Performance Measurement of Mining Equipments by Utilizing OEE. Acta Montanistica Slovaca, 15, 95-101.

Emovon, I., Lilly, M. T., \& Ogaji, S. O. T.-O. (2012). Design of Software for Maintenance Workforce Scheduling (A Case Study of Afam Power Station, Nigeria). Engineering, 4, 235-244. https://doi.org/10.4236/eng.2012.45031

ISO 14224 (2016). Petroleum, Petrochemical and Natural Gas Industries-Collection and Exchange of Reliability and Maintenance Data for Equipment (ISO 14224:2016). British Standards Institution.

Jia, C., \& Zhang, C. (2020). Joint Optimization of Maintenance Planning and Workforce Routing for a Geographically Distributed Networked Infrastructure. IISE Transactions, 52, 732-750. https://doi.org/10.1080/24725854.2019.1647478

Kansake, B. A., \& Suglo, R. S. (2015). Impact of Availability and Utilisation of Drill Rigs on Production at Kanjole Minerals Limited. International Journal of Science, Environment and Technology, 4, 1524-1537.

Nyota, B., \& Murigu, M. M. (2016). Analysis of Non-Productive Time in Geothermal Drilling Operations-A Case Study of Olkaria. 6th African Rift Geothermal Conference, Addis Ababa, Ethiopia, 2-4 November 2016, 1-8.

Pintelon, L. M., \& Gelders, L. F. (1992). Maintenance Management Decision Making. European Journal of Operational Research, 58, 301-317. https://doi.org/10.1016/0377-2217(92)90062-E

Sullivan, G. P., Pugh, R., Melendez, A. P., \& Hunt, W. D. (2010). Operations \& Maintenance Best Practices: A Guide to Achieving Operational Efficiency. Federal Energy Management Program (August 2010), 321. http://www1.eere.energy.gov/femp/pdfs/omguide_complete.pdf

Tambe, P. P., \& Kulkarni, M. S. (2016). Selective Maintenance Optimization under Schedule and Quality Constraints. International Journal of Quality and Reliability Management, 33, 1030-1059. https://doi.org/10.1108/IJQRM-10-2014-0153

Wakiru, J. M., Pintelon, L., Muchiri, P., \& Chemweno, P. (2020). Integrated Maintenance Policies for Performance Improvement of a Multi-Unit Repairable, One Product Manufacturing System. Production Planning and Control, 1-21. 
https://doi.org/10.1080/09537287.2020.1736684

Wakiru, J., Pintelon, L., Muchiri, P. N., \& Chemweno, P. K. (2019a). Maintenance Objective Selection Framework Applicable to Designing and Improving Maintenance Programs. International Journal of Engineering Research in Africa, 43, 127-144. https://doi.org/10.4028/www.scientific.net/JERA.43.127

Wakiru, J., Pintelon, L., Muchiri, P. N., \& Chemweno, P. K. (2019b). A Simulation-Based Optimization Approach Evaluating Maintenance and Spare Parts Demand Interaction Effects. International Journal of Production Economics, 208, 329-342. https://doi.org/10.1016/j.ijpe.2018.12.014

Wakiru, J., Pintelon, L., Muchiri, P. N., Chemweno, P. K., \& Mburu, S. (2020). Towards an Innovative Lubricant Condition Monitoring Strategy for Maintenance of Ageing Multi-Unit Systems. Reliability Engineering and System Safety, 204, Article ID: 107200. https://doi.org/10.1016/j.ress.2020.107200 